\title{
Learning and Instruction
}

\section{Congruence and friction between learning and teaching}

\author{
Jan D. Vermunt, Nico Verloop \\ Leiden University, ICLON - Graduate School of Education, P.O. Box 9555, 2300 RB Leiden, \\ The Netherlands
}

\begin{abstract}
Theories of learning and theories of teaching often originate and operate independently from one another. This article attempts to contribute to the integration of the two types of theories. First, the cognitive, affective and regulative activities students use to learn are analyzed. Next, different ways in which teachers can regulate the learning and thinking activities of students are discussed, as well as the teaching strategies they can use for that aim. The third part focuses on different ways in which student-regulation and teacher-regulation of learning act upon one another. Congruence and friction between these modes of control are discussed. From this interplay implications are derived for process-oriented teaching, aimed at promoting congruence and constructive friction, avoiding destructive friction and reducing the gap between learning and teaching. (C) 1999 Elsevier Science Ltd. All rights reserved.
\end{abstract}

\section{Introduction}

Until recently many theories of teaching took little account of the results of research on learning processes (e.g. see Duffy, Lowyck \& Jonassen, 1993). In many instructional theories, the teacher is the directing agency, who prescribes to a high degree what learners should do to realize the objectives presented by the teacher. This view of teaching, which is founded on the idea that teaching essentially comes down to the transmission of knowledge from an external source to the learner, has come under increasing pressure (e.g. Biggs, 1996). Brown, Collins and Duguid (1989) notice that teaching often leads to isolated and inert knowledge. According to them, knowledge domains acquired through education are often studied in isolation from one another and are therefore difficult to access. Inertness of knowledge refers 
to the problem, also known in working practice, that, although pupils and students have indeed acquired a lot of knowledge, they may not have acquired the capacity to apply this knowledge to solve problems in practice. Dahlgren (1984) showed that although university students were able to talk about their field of study in more complicated words after one year of studies, their misconceptions about fundamental phenomena in that field had not changed. The speed of technological, professional and societal changes also makes it necessary for people to be able to acquire new knowledge independently after their school careers.

In response to these problems of transmission-of-knowledge teaching theories, a lively discussion has recently arisen about the presuppositions of these theories. For instance, Bednar, Cunningham, Duffy \& Perry (1991) state that "learning" is not a passive, knowledge-consuming and externally directed process, but an active, constructive and self-directed process in which learners build up internal knowledge representations that are personal interpretations of their learning experiences. These representations change constantly on the basis of the meaning people attach to their experiences. Bednar et al. (1991) argue for consistently founding teaching models on a theory of student learning processes. The idea that teaching practices and theories of teaching should be based on knowledge and theories of how students learn can already be found in Gagné's work (Gagné, 1970). More recently, Glaser (1991) and Shuell (1993) again made a plea for the development of theories in which teaching and learning are more intertwined than is usually the case.

When learning is conceived more as self-regulated knowledge construction than as taking in already existing external knowledge, the role of teaching changes too, from transmission of knowledge to supporting and guiding self-regulated knowledge construction (e.g. Lonka, 1997). The processes of students' knowledge construction become the object of teachers' efforts. This calls for theories of teaching that are firmly based on an analysis of student learning processes (e.g. Duffy et al., 1993; Brown, 1994; De Corte, 1995). In this article, an attempt is made to sketch the beginnings of such a theory, focusing on the regulation dimension of teaching and learning. It starts with an analysis of the learning activities students engage in. Following Shuell's (1993) suggestion, special attention is paid to the joint effects that teaching and learning may have upon one another. Besides, we will focus on learning and teaching in upper secondary and higher education. Not all parts of the theory can be documented equally well with empirical research results yet. Therefore, the last section presents some directions in which future empirical research should go.

\section{Student-regulation of learning processes}

Teaching does not automatically lead to learning. The learning activities students engage in largely determine the quality of the learning outcomes they attain. The literature on student learning is extensive, and different researchers use different concepts for similar or partly overlapping learning activities. Pintrich (1994) compared several taxonomies of learning components and concluded that the common elements were students' knowledge base, their procedural skills, their self-regulation 
of learning, and their motivation and affect. The distinction between cognitive, metacognitive and affective/motivational components of learning can also be found in the work of several other researchers, e.g. Short and Weisberg-Benchell (1989) and Wagner and McCombs (1995). Therefore, a first organizing principle in the categorization of learning activities presented below concerns three types of learning activities: cognitive, affective and metacognitive (regulative). Cognitive processing activities are those thinking activities that students use to process subject matter and that lead directly to learning outcomes in terms of changes in students' knowledge base. Affective learning activities, which students employ to cope with emotions that arise during learning, lead to a mood that may foster or impair the progress of the learning process. Metacognitive regulation activities are those thinking activities students use to decide on learning contents, to exert control over their processing and affective activities and to steer the course and outcomes of their learning. Both affective and regulative learning activities lead indirectly to learning outcomes, via their influence on the processing of subject matter. Hence, the term "regulation" has two conceptualizations, at two different levels of specificity: (1) as one (metacognitive) type of learning activity, the others being cognitive and affective, and (2) in the more general sense of student-regulation of learning processes, which encompasses the three types of learning activities.

Processing, affective and regulative components of learning are often studied separately. In each domain, researchers have identified learning activities and strategies whose descriptions often show considerable overlap. The taxonomy presented below represents an attempt to reduce the overlap between categories as much as possible, while trying to maintain the variation at the same time. It should be stressed that the taxonomy is not the ultimate solution but a helpful balance between simplified dichotomous categories and complex and elaborate categorical systems. Finally, it should be stressed that the categories are neither exhaustive nor mutually exclusive. Compared to Shuell's (1996) taxonomy of learning functions, we tried to develop the categorical system explicitly from the viewpoint of three main learning components: cognitive processing, metacognitive regulation and affection/motivation. In Table 1, the various categories of learning activities are summarized.

Table 1

A Categorization of Learning Activities

\begin{tabular}{lll}
\hline Cognitive & Affective & Regulative \\
\hline Relating/structuring & Motivating/expecting & Orienting/planning \\
Analyzing & Concentrating/exerting effort & Monitoring/testing/diagnosing \\
Concretizing/applying & Attributing/judging oneself & Adjusting \\
Memorizing/rehearsing & Appraising & Evaluating/reflecting \\
Critical processing & Dealing with emotions & \\
Selecting & & \\
\hline
\end{tabular}




\subsection{Cognitive processing activities}

The first kind of learning activities are the ones students engage in to process subject matter and that lead directly to learning outcomes in terms of changes in students' knowledge base, such as knowledge, understanding and skill. An analysis of the research literature on the nature of these thinking activities showed that different researchers used different categorizations to group partly overlapping processing activities. The following six categories represent the most important similarities and differences among the various conceptualizations (e.g. Pask, 1976; Marton, 1988; Schmeck et al., 1991; Entwistle, 1995; Meyer, 1996).

Relating/structuring: Looking for connections between different parts of the subject matter, between the parts and the whole, the broad outline of the learning materials, and between new information and prior knowledge or preconceptions. "Structuring" refers to bringing together separate parts of information into an organized whole, trying to impose structure on the learning contents, and integrating newly acquired knowledge into the knowledge one already has. Examples of "relating" activities are that students try to think of analogies between problems in the subject domain, examine the similarities and differences between theories or learning experiences, and compare the information from the course materials with knowledge they have from other sources (Entwistle, 1995). Examples of "structuring" activities are that students represent the main concepts in an article and their interrelations into a clearly arranged scheme, try to form an overview of a course and order subjects that are dealt with independently under super-ordinate principles or themes (e.g. Kirby \& Pedwell, 1991).

Analyzing: Breaking down a larger whole into the parts of which it is composed, sorting out step by step what different aspects of a problem, line of thought or theory may be discerned. Examples are that students thoroughly study specific details and factual information, examine the successive steps in an argument, and study a textbook chapter by chapter, stepwise and in detail. This is a way of information processing that Pask (1976) called "serialistic": going through the learning materials in a serial, sequential manner, without thinking much about broader relations within the domain.

Concretizing/applying: Trying to form concrete images from abstract information, borrowed from phenomena one is familiar with, and trying to use knowledge one has acquired. In essence, this category boils down to looking for "external" relations of the subject matter: seeking the relevance of what one learns in the outer world. Concretizing activities include thinking of examples and practical applications, comparing information in the subject matter with personal experiences, and connecting subjects with phenomena in everyday reality (Schmeck et al., 1991). "Applying" occurs, for example, when students try to use the knowledge they acquired through study to understand the surrounding (social, legal, physical, chemical, etc) world in a new way, use subject matter to interpret experiences and topical events in their subject domain, and try to solve problems making use of what they learned (Marton, 1988).

Memorizing/rehearsing: Imprinting separate information by repeating it a number 
of times, and rehearsing subject matter. This category comprises activities such as learning definitions, formulas and characteristics by heart, memorizing theories, views and conclusions, and rehearsing the subject matter regularly until it can be reproduced (Schmeck et al., 1991).

Processing critically: Thinking along with authors, teachers and fellow students, drawing one's own conclusions based on facts and arguments, rather than just accepting anything that is said or written. Examples are that students examine whether conclusions and views of other people are in accordance with the facts, sort out things themselves, form their own interpretations and opinions, and form a personal judgment of the correctness of information presented (Paul, 1990). Marton (1988) describes this mode of learning as "being active".

Selecting: Distinguishing between main and minor points, reducing large amounts of information to the most important parts. Students often do this by marking or underlining central concepts in their textbooks, studying some parts more carefully than other parts, making notes and paying special attention to certain types of information in the subject matter, such as facts and definitions, broad outlines, or practical solution methods (Schellings et al., 1996).

\subsection{Affective learning activities}

The second type of learning activities is related to the role of affective variables in learning processes. These affective learning activities, which students employ to cope with emotions that arise during learning, lead to a mood that may have a positive, neutral or negative effect on the progress of learning processes. The following classification is an attempt to categorize the various affective learning activities found in research literature into a limited number of qualitatively different categories (e.g. see McCombs, 1991; Scardamalia \& Bereiter, 1994; Boekaerts, 1995; Snow, Corno \& Jackson, 1996).

Motivating/expecting: Building up and maintaining willingness to learn, and forming expectations about the course and outcomes of a learning process. Motivating may refer to general as well as task-specific learning motivation. Examples are that students reward themselves when they attain certain subgoals, think of the negative consequences when they want to quit learning, and try to generate interest in a subject (Hidi, 1990). Failure expectations are, for example, that students think they cannot successfully complete a learning task, because it is too difficult and the learning goals are not attainable, whereas the reverse is true for success expectations.

Concentrating/exerting effort: Directing attention to task-relevant aspects and coping with action-distracting, task-irrelevant thoughts and emotions, performing thinking activities that require mental energy. This is, for example, the case when students eliminate their desire to do alternative things, increase the intensity of attention when they have already been working concentratedly for a long time, and persist in their task execution when problems arise (e.g. Reynolds \& Shirey, 1988). Energetic aspects of learning include the nature and amount of mental effort invested by learners. Sometimes, thinking activities may be performed almost automatically (e.g. 
with routine learning tasks); on other occasions they require more constructive effort and mindful, metacognitive regulation (e.g. with novel, difficult tasks) (Lonka, 1997).

Attributing/judging oneself: Ascribing learning outcomes to causal factors: stable versus variable, controllable versus uncontrollable, general versus specific, and internal versus external; deriving judgments about oneself as a learner. These judgments may refer to one's general subjective competence or to self-efficacy with respect to certain subjects. For example, students may ascribe failure experiences to a lack of effort, a variable, controllable, specific, internal factor, or to a lack of ability. Success experiences may, for example, be ascribed to the quality of instruction, to chance, or to the use of the right learning activities (Weiner, 1994). Examples of judgmental processes are that students judge their capacity for self-regulated learning, Mathematics or a single task as high or low. They contribute to a self-concept or self-image (Zimmerman \& Bandura, 1994).

Appraising: Attaching subjective values to learning tasks resulting in the willingness or unwillingness to invest energy. This category includes the way in which learners appraise the task relevance, the time and mental effort needed to perform certain learning activities, and the contribution of a learning task to the attainment of personal goals (Boekaerts, 1995).

Dealing with emotions: Generating, maintaining and restoring positive feelings of well-being, self-confidence and commitment, and coping with negative emotions such as anxiety, fear, anger, stress, uncertainty, doubt, frustration and helplessness. Activities within his category are talking to oneself in a reassuring way, avoiding stress, and setting realistic learning goals (Snow et al., 1996).

\subsection{Metacognitive regulation activities}

Metacognitive regulation of learning processes refers to exerting control over one's own cognitive and affective processing of subject matter. Such self-regulation means, for example, the flexible employment of different processing activities, depending on circumstances and on interim learning outcomes. Metacognitive activities constitute a third type of learning activities. The following categorization is based on an analysis of the relevant research literature (e.g. Brown, 1987; Iran-Nejad, 1990; Zimmerman \& Bandura, 1994).

Orienting/planning: Preparing a learning process by examining characteristics of the learning task, situation and assessment, and thinking of possible learning goals, contents and processing activities, necessary resources, prior knowledge and available time (Simons, 1993). Then, designing a learning process and deciding on a plan of action, based on the information that the orientation provides. Examples are deciding on the learning goals, resources, learning contents, the processing activities that are most suitable for attaining the learning goals, the sequence of learning activities and learning tasks and the time to be spent on every part of the task (Volet, 1990).

Monitoring/testing/diagnosing: Observing, during task performance, whether the learning process proceeds according to plan. Monitoring means that learners actively observe whether their learning activities lead to progress in the intended direction. Activities within this category are that students notice they do not understand some- 
thing very well, perceive that they get nervous, and observe that they have already read a text four times without knowing what it is about (Winne, 1995). Testing is a more explicit way of checking whether one understands, can remember or apply the subject matter sufficiently, and whether the actually realized learning outcomes are similar to those one had in mind. Examples are asking questions and trying to answer them, trying to explain in one's own words what is meant, and trying to reproduce definitions, formulas, characteristics and facts (Rosenshine et al., 1996). Diagnosing refers to determining gaps in one's own knowledge, skills and mastery of the subject matter, and examining possible causes of learning difficulties or successes. Examples are that students examine why they do not understand something, trace the cause of their inability to solve a problem, and try to find out what exactly they do or do not understand or remember (Vermunt, 1996).

Adjusting: Introducing changes in the original learning plan on the basis of the results of monitoring, testing and diagnostic activities, deciding on alternative learning activities, goals and/or contents during learning. Other activities within this category are maintaining one's motivation, asking for help, paying extra attention to certain parts of the subject matter, updating one's own prior knowledge, changing one's learning goals, trying out other learning activities, spending more time on learning, and skipping a part of the subject matter. During a learning process, learners continually adapt their goals and criteria for testing their learning outcomes (Volet, 1990).

Evaluating/reflecting: Evaluating pertains to judging the extent to which the final learning outcomes are in agreement with the goals that were planned, and the degree to which the learning process has proceeded as imagined in advance. Activities within this category are, for example, making trial exams, trying to explain the main points of a course in one's own words, and trying to answer questions from fellow students about the subject matter. Reflecting is manifested in thinking over the things that have happened during the learning process and thinking about learning, teaching, learning activities and learning experiences in general. Examples are that students think about the approach to learning they adopted, about which learning activities could be tried a next time, and about the usefulness of co-operation with fellow students. In this way, experiential knowledge is acquired that can be used in future learning processes (Von Wright, 1992).

\subsection{Learning strategies, styles, conceptions and orientations}

Learning activities as described above are not triggered directly by teaching activities. Students' learning conceptions, or mental models of learning, determine what they understand by "learning" and in what way they interpret learning objectives, learning tasks and teaching measures (Säljö, 1979; Lonka \& Lindblom-Ylänne, 1996). These mediating interpretations and perceptions, then, lead to the learning activities students employ (e.g. Lowyck \& Elen, 1993). Learning activities are also influenced by students' learning orientations. These orientations refer to the whole domain of students' personal goals, intentions, motives, expectations, attitudes, concerns and doubts in education or a course (Gibbs et al., 1984). They seem to exert 
their influence on the learning activities students employ mainly through affective processes, especially the values students attach to a learning situation or task (Dweck, 1989). Learning strategies are seen here as particular combinations of learning activities students use to achieve their learning goals. For example, a deep processing strategy combines the use of relating, structuring and critical processing activities (Vermunt, 1996). Vermetten, Lodewijks and Vermunt (1997) found both consistency and variability in students' learning strategy usage across learning situations. Usually, the concept of learning style refers to the consistent aspects of students' learning activities (e.g. Moran, 1991). Here, the concept is used in a broader sense and also includes students' learning conceptions and orientations. "Learning style" is viewed here as a coherent whole of learning activities that students usually employ and their learning orientation and their conception of learning; this whole is characteristic of them in a certain period of time. Various studies showed strong relations among the learning activities and strategies higher education students employed and their learning conceptions and orientations (e.g. Lonka \& Lindblom-Ylänne, 1996).

In his research, Vermunt $(1996,1998)$ found four qualitatively different learning styles as conceptualized above: undirected, reproduction-directed, meaning-directed and application-directed learning. The undirected learning style is characterized by an experienced lack of regulation, an ambivalent learning orientation, and a learning conception in which great value is attached to the learning support that fellow students and teachers can provide. This way of learning resembles Meyer and Cleary's (1997) disorganized study orchestration. The reproduction-directed learning style shows strong associations between the use of a stepwise processing strategy (analyzing, memorizing) and an external regulation strategy (letting one's own learning processes be regulated by external sources), a learning conception in which learning is viewed as the intake of knowledge provided by teachers, and a learning orientation toward testing one's capabilities and gaining certificates. The use of a deep processing strategy (relating, structuring, critical processing), self-regulation of one's own learning processes, a learning conception in which learning is seen as constructing one's own knowledge, and a personally interested learning orientation together define the meaning-directed learning style. The last two styles have family resemblances to Biggs (1987) and Entwistle's (1992) meaning and reproducing orientations. The application-directed learning style combines concrete processing (concretizing, applying), a conception of learning in which the use of knowledge is stressed, and a vocational learning orientation. This resembles an orientation found by Lonka and Lindblom-Ylänne (1996), which they call an active professional orientation.

\section{Teacher-regulation of learning processes}

Learning is viewed here as developing a way of thinking and acting that is characteristic of an expert community. Such a way of thinking consists of two important elements: the knowledge that represents phenomena in the subject domain, and the thinking activities that construe, modify and use this knowledge to interpret situations 
in that domain and to act in them (Billett, 1996). Accordingly, teaching is viewed as stimulating learners to employ suitable thinking activities to construct, change and utilize their knowledge. Knowledge and thinking strategies are taught in coherence. This type of teaching is named process-oriented, because it focuses on the processes of knowledge construction and utilization (e.g. Applebee \& Langer, 1983; Volet et al., 1995; Vermunt, 1995).

The categories and descriptions of learning activities so far were based on the literature on student learning. Studying the literature on teaching and teaching activities, it is striking that, in the domain of teaching, categories show up that are very similar to those in the domain of learning. Rosenshine \& Stevens (1986) mention as examples of important teaching activities, explaining relationships within the subject matter, giving examples, planning the learning process, and motivating students. In many teaching theories and teachers' handbooks, these activities are described as didactic skills. It seems that learning and teaching activities are one another's mirror image and may be described in the same terms. Hence, one can speak of learning functions, psychological functions that have to be fulfilled for high-quality learning to take place (Shuell, 1993; Simons, 1993). They can be divided in processing, affective and regulation functions. The processing function of teaching concerns presenting and clarifying the subject matter. The affective function refers to creating and maintaining a positive motivational and emotional climate for learners. The regulation function is aimed at steering students' learning processes. From the viewpoint of influence on the thinking activities students use to learn, different teaching strategies can be used. They constitute different levels of external regulation and therefore also of the degree of control students are expected to exert over their own learning.

In general, teaching methods can be placed on a dimension ranging from very strongly teacher-regulated to very loosely teacher-regulated (e.g. Bereiter \& Scardamalia, 1989). Many positions are possible on this dimension. For reasons of clarity, we will single out three positions for discussion: strong, shared and loose teacher control (compare Biggs, 1996). In the case of loose teacher control, the need for student-regulation of learning is high. This does not mean, of course, that all teaching can be categorized into just three groups. In addition, we do not define "teacher control" as only the teacher's activities, but also as the control that is exerted by the task, instructional materials, in-text teaching devices, computer system, and other regulating elements in the learning environment. Since our main focus is on the internal-external regulation dimension, the way these other instructional agents regulate or shape student learning is included under the general term "teaching".

According to Shuell (1996), learning functions can be "teacher initiated" and "learner initiated". Under the heading of "teacher initiated", he gives examples of both substituting the learning function for the learner (e.g. "provide overview of the material to be studied") and activating students to use a particular learning function (e.g. "encourage comparison through the use of questions"). Below, we will differentiate these two forms of teacher initiation in terms of substituting learning functions for students ("strong teacher control") and activating learning functions in students ("shared control"), because we believe their effect on student learning is psychologically different. Moreover, we based the categorization of learning functions on the 
analysis of learning activities discussed in the first part of this article. When a learning function is performed by the learner, one may speak of a learning activity. Finally, for theoretical reasons discussed above, we ordered the learning functions in such a way that they mirror the distinction between students' cognitive, affective, and regulative learning activities.

\subsection{Teacher-regulation strategies}

In the first strategy, the teacher tries to perform the learning functions, and hence there is a strong teacher control: the teacher tries to take over, or substitute, cognitive, affective and metacognitive activities from students. Table 2 gives examples of this teaching strategy for every learning function. This strategy is employed by teachers to clarify the subject matter and to facilitate, regulate and control students' processing of this subject matter. In this way, teachers take learning activities out of the students' hands by performing these for them and, in doing so, minimize the need for students to utilize their thinking strategies. Instructional activities such as "presenting an outline", "providing students with examples" and "highlighting main points" belong to this strategy. They correspond with the substitution of the learning functions "structuring", "concretizing" and "selecting", respectively. The presentation of analogies as an aid to understanding, (e.g. Halpern et al., 1990) represents, in this line of reasoning, the substitution of the learning function "relating".

It is characteristic of the second strategy that the responsibility for performing the functions is handed over to the students. Here, the teacher assumes that students will employ the right learning and thinking activities on their own initiative when learning. There is loose teacher control. Examples are given in the first part of this article under "student-regulation of learning processes". In the extreme case, teachers limit themselves to presenting the subject matter and testing the learning outcomes. The call on students' thinking activities is maximum. They are expected to be able to cognitively and affectively process the subject matter and to regulate their learning processes. In doing so, the teacher capitalizes on students' supposed skill in selfregulated learning and thinking, in independent performance of learning functions. When this teaching strategy is in operation, the need for what Shuell (1996) calls "learner-initiated use of learning functions" is maximum: learners have to motivate themselves, look for similarities ("relating"), monitor performance, self-test their progress, etcetera. In less extreme cases, teachers monitor the self-regulated learning of students and provide feedback and assistance when needed.

In the third teaching strategy, the responsibility for performing the learning functions is shared between teachers and students, and hence one can speak of shared control. Students are continually activated to carry out the various learning functions when learning (Entwistle, 1992; Lonka \& Ahola, 1995). Examples of this teaching strategy for every learning function are presented in Table 3. In all these examples, teachers stimulate students to employ certain cognitive, affective and metacognitive activities to learn. This may be done implicitly, for example, by building up an argument in such a way that students are encouraged to think along, or explicitly by asking questions and giving assignments or tasks. When students have some 
Table 2

Examples of Teacher Substitution of Learning Functions in a Strong Teacher-Regulation Form of Instruction

\begin{tabular}{l} 
Learning function \\
\hline Cognitive \\
Relating/structuring \\
Analyzing \\
Concretizing/applying \\
Memorizing/rehearsing \\
Critical processing
\end{tabular}

Selecting

Affective
Motivating/expecting

Concentrating/exerting effort

Attributing/judging oneself

Appraising

Dealing with emotions

Regulative

Orienting/planning

Monitoring/testing/diagnosing

Adjusting

Evaluating/reflecting

Teaching activity

Presenting and clarifying the subject matter Explaining relationships, giving analogies. Presenting overviews, summaries, schemes.

Explaining in detail, step by step.

Offering examples, applications, illustrations, indicating relations with practice, interpretations of actual events.

Rehearsing the subject matter regularly, giving rehearsal units.

Telling arguments in favour of and against a point of view, pointing out different possible conclusions.

Revealing the main and minor points, marking central concepts.

Creating a promoting affective climate

Presenting the learning content in a captivating way, generating interest. Making students believe in their own capabilities.

Directing attention to task-relevant aspects, building in variation and pauses. Giving tasks and assignments that require mental effort.

Giving realistic attributions, ascribing failure to controllable factors. Giving constructive judgments.

Pointing out the relevance of a course or task.

Reassuring learners, reducing fear and anxiety.

Regulating learning processes

Giving introductions, ascertaining prior knowledge. Informing learners of the learning objectives, contents and activities.

Observing students' facial expressions, asking questions. Administering tests, making students solve practical problems. Examining the kind and cause of problems with understanding.

Giving additional explanations, changing tasks and assignments.

Administering summative tests, supplying sample exams. Giving feedback on learning and suggestions for improvement in the future. 
Table 3

Examples of Teacher Activation of Learning Functions in a Shared-Regulation Form of Instruction

\begin{tabular}{|c|c|}
\hline Learning function & Teaching activity \\
\hline Cognitive & Presenting and clarifying the subject matter \\
\hline Relating/structuring & $\begin{array}{l}\text { Asking for similarities and differences between } \\
\text { theories. Instructing to make an overview. }\end{array}$ \\
\hline Analyzing & Asking detailed questions. \\
\hline Concretizing/applying & $\begin{array}{l}\text { Having students make connections with their } \\
\text { own experiences. Letting students solve a problem, } \\
\text { asking for practical meaning. }\end{array}$ \\
\hline Memorizing/rehearsing & $\begin{array}{l}\text { Administering exams that test factual } \\
\text { knowledge. }\end{array}$ \\
\hline Processing critically & $\begin{array}{l}\text { Having students present arguments, presenting } \\
\text { conflicting views, organizing a group discussion. }\end{array}$ \\
\hline Selecting & Asking for main points and central concepts. \\
\hline Affective & Creating a promoting affective climate \\
\hline Motivating/expecting & $\begin{array}{l}\text { Giving students personal responsibility for their } \\
\text { learning. Giving tasks students can handle. }\end{array}$ \\
\hline Concentrating/exerting effort & $\begin{array}{l}\text { Recommending not to study too long in } \\
\text { succession. Making students talk about the results } \\
\text { of their thinking process in a group. }\end{array}$ \\
\hline Attributing/judging oneself & $\begin{array}{l}\text { Stimulating students to make attributions based } \\
\text { on a realistic diagnosis, to estimate their } \\
\text { competence and self-efficacy highly. }\end{array}$ \\
\hline Appraising & $\begin{array}{l}\text { Emphasizing the importance of a task to realize } \\
\text { personal goals. }\end{array}$ \\
\hline Dealing with emotions & $\begin{array}{l}\text { Having students experience success, praising } \\
\text { them. }\end{array}$ \\
\hline Regulative & Regulating learning processes \\
\hline Orienting/planning & $\begin{array}{l}\text { Activating students' prior knowledge. Giving } \\
\text { students freedom of choice in subject matter, } \\
\text { objectives and activities. }\end{array}$ \\
\hline Monitoring/testing/diagnosing & $\begin{array}{l}\text { Making students monitor each other's process. } \\
\text { Letting students invent test questions. Making } \\
\text { them analyze the cause of problems. }\end{array}$ \\
\hline Adjusting & $\begin{array}{l}\text { Encouraging students to search for solutions on } \\
\text { their own with difficulties, having them tackle } \\
\text { problems together. }\end{array}$ \\
\hline Evaluating/reflecting & $\begin{array}{l}\text { Letting students compose an exam and take one } \\
\text { another's exam. Instructing to compare their own } \\
\text { approach with that of others. }\end{array}$ \\
\hline
\end{tabular}


responsibility for their learning processes and can take some decisions, they are stimulated to employ regulation strategies and to increase their skill in using them. In this teaching strategy, it is the students' task to carry out the learning functions and the teacher's task to activate students to do so. Instructional activities such as "ask students to summarize" (Rosenshine \& Stevens, 1986) or "encourage students to evaluate their performance" (Shuell, 1996) are two instances of this category of shared-control teaching strategies.

From the perspective of influence on the learning activities that students employ, every form of teaching may be characterized by a three (teaching strategies) by fifteen (learning functions) matrix. Numerous variations and combinations are possible. In practice, there is always a task division between teachers and students in fulfilling learning functions. This means that, on a dimension from teacher-regulated to student-regulated learning, many intermediate positions are possible. The teacher may, for example, capitalize on skills concerning the affective processes and the regulation of learning, but substitute cognitive processing activities. In this case, there is a mixed control. This kind of teaching is quite common in the first years of higher education. Here, lecturers explain many relations between theories and give examples, etc, but they view the affective learning activities and the regulation of the independent preparation for an exam as students' tasks. Moreover, the teacher may decide not to explain the relationships between two theories, because the authors of the textbook did a good job in that respect. In this case, there is a task division between the different instructional agents in fulfilling one particular learning function. Complete teacher control or the total absence of teacher control rarely occur. Going to school or university means almost by definition that students want their learning processes to be teacher-regulated to a certain degree. On the other hand, there can be no learning if students are not capable or willing to employ any thinking activity.

In considering the advantages and disadvantages of these three teaching strategies, one may focus on the effects in terms of gains students achieve in their knowledge or understanding of the subject matter, as well as on the effects in terms of gains they achieve in their mastery of learning functions. Of course, the latter gains ultimately have to result in gains in knowledge and understanding of new subject matter as well, as a result of more self-regulated usage of these learning functions. Below, in the section on interplay between self-regulation and external regulation of learning, we will discuss the advantages and disadvantages of these strategies in terms of both types of effects.

Teachers' ways of teaching often show consistency over time. These habitual patterns of teaching are connected with teachers' mental models of teaching ("craft knowledge" or "practical knowledge", see Beijaard \& Verloop, 1996; Prosser et al., 1994) and with their teaching orientations. If teachers employ a teaching strategy with some consistency, one may speak of a teaching style. If, for example, teachers consistently take over many thinking activities from students, they employ a substituting teaching style. 


\section{The interplay between teacher-regulation and student-regulation of learning}

Teaching strategies and learning strategies are not always compatible. Between students' self-regulation and teachers' external regulation of learning processes, complex interplays may take place. Congruence occurs when students' learning strategies and teachers' teaching strategies are compatible; friction occurs when this is not the case. The outcomes of congruence are denoted as mathemagenic effects. Friction results in interference phenomena, also called mathemathantic effects (Lohman, 1986; Clark, 1990; Janssen, 1996). These occur if a teaching strategy has negative effects on the learning process, learning outcomes or the learning and thinking skills of students, or if teaching gives rise to, or maintains, misconceptions (e.g. Schoenfeld, 1988). From the viewpoint of influence on the learning and thinking activities students employ, constructive and destructive frictions may be discerned. Constructive frictions represent a challenge for students to increase their skill in a learning or thinking strategy. These may be necessary to make students willing to change and to stimulate them to develop skill in the use of learning and thinking activities they are not inclined to use on their own. Destructive frictions may cause a decrease in learning or thinking skills. Here, existing learning and thinking skills are not called upon or potential skills are not developed.

As is the case with teacher-regulation of learning processes, the degree of selfregulation of learning that students are capable of can be represented by a continuum ranging from very little to very high, with all intermediate positions possible. For the same reason of clarity that made us single out three positions on the teacherregulation continuum, we will discuss three positions on the self-regulation continuum. The first is that students master a learning activity well and use it skilfully and on their own initiative (high degree of self-regulation). In the second case, students master a learning activity only to a limited extent, or they master it well but do not use it spontaneously, in the right situations or sufficiently skilfully in the subject domain (intermediate degree). In the last case, they do not master nor use a particular learning activity (low degree).

In Table 4, possible interplays between student-regulation and teacher-regulation of learning processes are presented. Teaching and learning strategies are congruent

Table 4

Interplays between Three Levels of Teacher-Regulation and Three Levels of Student-Regulation of Learning Processes

\begin{tabular}{llll}
\hline \multirow{2}{*}{$\begin{array}{l}\text { Degree of student- } \\
\text { regulation of learning }\end{array}$} & \multicolumn{2}{l}{ Degree of teacher-regulation of learning } & \\
\cline { 2 - 4 } & Strong & Shared & Loose \\
\hline $\begin{array}{l}\text { High } \\
\text { Low }\end{array}$ & $\begin{array}{l}\text { Destructive friction } \\
\text { Destructive friction } \\
\text { Congruence }\end{array}$ & $\begin{array}{l}\text { Destructive friction } \\
\text { Congruence } \\
\text { Constructive friction }\end{array}$ & $\begin{array}{l}\text { Congruence } \\
\text { Constructive friction } \\
\text { Destructive friction }\end{array}$ \\
\hline
\end{tabular}


on one diagonal. For example, if students are not very well capable of regulating their own learning and the teacher does it for them, teaching and learning strategies are balanced for that moment. The majority of cells, six out of nine, represent friction between teaching and learning. Some of these are destructive in nature, for example when students that are well capable of self-regulated learning have a teacher who prescribes the way they should learn in detail. Others are constructive, in the sense that they challenge students to try new ways of learning and thinking.

The scheme depicted in Table 4 can be understood at various levels of specificity. At a general level, "degree of student-regulation of learning" signifies students' general capability to self-regulate their learning processes. This refers to their skill in employing the total set of learning activities. At a more specific level, it refers to students' skill in a particular learning strategy, represented by a subset of learning activities. For example, students may be good at the self-regulated use of relating, structuring, and critical processing activities (deep processing strategy), but far less skilled in concretizing and applying activities (concrete processing strategy). At the most specific level, the scheme may refer to students' skill in the self-regulated use of one particular learning activity, e.g. "planning", or "selecting", or "motivating".

Strong teacher-regulation. If the teacher utilizes a strong teacher-regulated form of instruction, congruence between learning and teaching occurs when students do not master a particular learning activity. This is the case, for instance, when students are not looking for relations within the subject matter and the teacher explains these relations, or when students are not motivated and the teacher employs strategies to enhance their motivation. Friction between a strongly controlling teaching strategy and students' learning strategies may be expected to occur when students master and use a learning strategy well (Hamaker, 1986). This is the case, for example, if students are well capable of self-regulating their learning process in a particular domain but the teacher or textbook prescribes in detail what, how and in what order the student should learn. In this case, a decrease in the learning or thinking skill may take place for the students, which is caused by a lack of application. Clark (1990), for example, traced studies in which instruction actually deteriorated learning. On the basis of a review of these studies, he concluded that these mathemathantic effects occur when the instructional agent tries to take over learning strategies from students and when this agent tries to substitute student control by system control, in those cases in which students are well able to perform these functions themselves. Entwistle (1992) also warns against the interfering effects of taking over too many learning activities from students. According to him, detailed hand-outs, for example, of which it is assumed that they foster student learning, may cause dependence. Students begin to think that reproducing the information as provided by the teacher is all that is expected of them. Friction also occurs with this teaching strategy when students master a learning activity to an intermediate extent. In this case, students are hindered in further developing their skill. This is the case, for example, when students who are in the process of developing skill in self-diagnostic regulation activities enter a learning environment in which these diagnostic functions are taken over by the teacher. Shuell (1996, p. 758) warns that care should be taken to prevent students from becoming dependent on the instructional strategies employed by the 
teacher for learning new material and skills. Both types of frictions are of a destructive nature (see Table 4).

In summary, a strong teacher-regulation strategy may be necessary if students are unable to employ particular learning activities that are important for the material to be learnt. If a student fails to see the relations between two theories and the teacher or textbook explains these relations, the student learns to know about these relations: there is a gain in knowledge. If the teacher continues substituting this learning function, however, students are not stimulated to develop their expertise in self-regulated use of the learning activity. There is no gain in the skill of employing the learning activity for self-regulated knowledge construction. If, however, the teacher not only explains the relations between two theories, but also explains how he or she came to see those relations, or shows the act of "relating" the theories in vivo by thinking aloud, this substituting strategy may well get a modelling function.

Shared regulation. If the teacher uses a shared regulation form of instruction, congruence between learning and teaching occurs when the students master a learning activity to an intermediate degree. An example of this is that students do not process the subject matter critically on their own initiative, but are nevertheless stimulated by a group discussion to draw their own conclusions and to form personal judgments (Lonka \& Ahola, 1995). In this shared-control strategy, constructive friction will take place if students do not master a learning or thinking activity in the subject domain at hand. For example, the teacher asks the students to think of examples, while they are not used to doing so. These constructive frictions represent situations in which students are unable to use a certain learning activity independently but are able to do so with the guidance of an expert [compare Vygotsky's zone of proximal development (Vygotsky, 1978), and Palincsar and Brown's (1989) procedures for reciprocal teaching of comprehension-monitoring activities]. Destructive friction may be expected if students master a learning or thinking activity well and use it spontaneously in the right situations. One can imagine that students who are well capable of the self-regulated use of particular learning activities get irritated and off balance if the teacher continually stimulates them to employ these learning activities (e.g. Lohman, 1986). This is a situation, however, that is quite common in higher education. For example, in higher vocational education, students' learning styles are often application-directed in nature. This means that learning activities like concretizing and applying are learner-initiated: students do not have to be stimulated to think about the applicability of what they learn. However, many teachers in higher vocational education have an application-oriented way of teaching: they give many tasks, questions and assignments in which students are asked for possible examples and applications of what they learn. It seems superfluous to stimulate students to employ learning activities they use on their own initiative. In these situations, other learning activities, like structuring concepts, relating theories, critical processing of ideas, are often no part of the learning process: students do not use them on their own initiative, and teachers do not stimulate students to use them.

In sum, the shared-control strategy is best suited for those situations in which students have already acquired some skill in employing a particular learning activity, but have a need for further skill development. Furthermore, it is well suited to chal- 
lenging students to try new forms of learning in which they cannot utilize learning activities they are familiar with (e.g. memorizing). It is less suited for situations in which students have already acquired expertise in the self-regulated use of particular learning activities.

Loose teacher-regulation. When the teacher uses a loose teacher-regulated form of instruction, congruence between learning and teaching occurs if students master a learning strategy well and use it on their own initiative and in the right situations (Simons, 1993). This is the case, for example, when teachers do not undertake any activities to regulate students' learning processes during their independent studying of texts, and students have the necessary regulatory skills at their disposal. Another example is a teacher who knows that students, in a certain domain, are well capable of generating concrete examples, and therefor does not provide any of these. Friction may be expected when students do not master the learning or thinking strategies that are called upon. This is, for example, the case when the teacher capitalizes on selfregulated strategies but students are incapable of performing these, want to use an externally regulated strategy but do not get enough directions for doing so. Ertmer, Newby and MacDougall (1996) documented such a phenomenon in the differential reactions to a case-based instructional approach of students differing in self-regulatory skills. If the degree of students' self-regulation is inadequate and the teacherregulation is deficient, too, the danger of a lack of regulation is present (compare Meyer \& Cleary, 1997). If students do not master the learning or thinking activities on which the teacher capitalizes, there is destructive friction. This was often the case in traditional university education, in which students were informed about the textbooks they should master and about the date the exam would take place. For many of these students, however, the distance between this highly self-regulated form of learning that was expected and their teacher-dependent way of learning they were used to in secondary school was too high, resulting in drop-out. If students master a strategy to some extent, there may be constructive friction.

In sum, this strategy seems appropriate if students are proficient in the use of particular learning activities, or if they are on their way to getting proficient. It allows the teacher to pay attention to other learning functions than to those the students already master sufficiently for the domain at hand. It is not suitable in situations were students' skill in regulation of learning is low, either in general or with respect to particular important learning activities.

If the goal of teaching is not only to achieve gains in knowledge or understanding of subject matter, but also gains in the ability to self-regulated knowledge construction, one has to look for ways of combining the strong points of the interplays between teaching and learning described above. The central issue, then, becomes the development from teacher-regulated to student-regulated learning.

\section{Process-oriented teaching: from teacher-regulation to student-regulation of learning processes}

Destructive frictions often take place. Teachers and designers of instruction, for instance, frequently have the tendency to take over as many learning and thinking 
activities from students as possible (Bednar et al., 1991; Sternberg \& Horvath, 1995). Process-oriented teaching tries to promote congruence and constructive friction, and to avoid destructive friction. The aim is to teach domain-specific knowledge and the learning and thinking strategies that students need to construct, change and utilize their knowledge of the subject domain, in coherence (Vermunt, 1995). The emphasis is on a gradual transfer of learning functions from teachers to students. In terms of development in student' learning styles, process-oriented teaching aims at stimulating the development of meaning and application-directed learning styles and discouraging undirected and reproduction-directed ways of learning. The main tasks for teachers in this view are initiating, supporting and influencing the thinking processes that students use to learn (Simons, 1993). Elsewhere, principles of process-oriented teaching are discussed more extensively (e.g. Vermunt, 1995; Volet et al., 1995). Here, we will focus on the implications for the roles of teachers in regulating students' learning processes.

(1) Teacher as diagnostician. Much more than in the knowledge transmission model, in process-oriented instruction, teachers have to develop skills in diagnosing students' learning and thinking strategies. Because the occurrence of frictions originates from a certain combination of teaching strategies with students' learning strategies, adequate diagnoses of students' learning and thinking strategies are a necessary condition to avoid these frictions and to be able to tailor teaching to those strategies students do not master or master insufficiently (Kember, 1991). For example, this diagnosis may show that, in a particular domain, students are quite skilled in discovering conceptual similarities and differences between various theories on a subject ("relating/structuring"), but not very good at translating these conceptual theories into practical applications ("concretizing/applying").

(2) Teacher as challenger. Teachers have to challenge students to try out new learning and thinking strategies. This means, for example, giving learning tasks to students they cannot do well with the strategies they normally use (creating constructive friction). Students then start reflecting on their current approach and exploring alternative learning and thinking strategies, a phase in which they are most susceptible to new possibilities (Collins et al., 1989). Friction often occurs when students enter a new type of education, for instance after the transition from secondary to higher education. An example of a teacher-created constructive friction is to ask students who are good at memorizing to discuss the arguments pro and contra a certain point of view, after this critical processing has been modeled to the students in some way (e.g. by the teacher or fellow students), or to ask students who prefer to get specific guidelines for approaching learning tasks to make an approach plan themselves.

(3) Teacher as model learner. Teachers should demonstrate the use of learning and thinking strategies important for the subject domain, so students can develop a clear picture of what a certain strategy means and how it can be used. By demonstrating the different activities by which subject matter may be processed, problems solved, and learning processes regulated, the teacher makes knowledge construction and utilization activities overt and explicit that usually stay covert and implicit (Palincsar \& Brown, 1989; Volet, 1991; Scardamalia \& Bereiter, 1994). By thinking 
aloud, for example, the teacher shows students how they can structure the central concepts of a domain into a scheme, think of concrete examples with difficult subject matter, motivate themselves and concentrate, and test their understanding of the subject matter. By demonstrating these learning activities within the context of subject matter teaching, students are confronted with a broad variety of examples from the different subject domains.

(4) Teacher as activator. When students have a clear idea of the content and use of certain learning strategies, teachers should activate students to use these strategies in learning about the particular subject domain. By means of questions, assignments, tasks, ways of presenting an argument, etc, students are stimulated to use thinking activities they do not usually employ when learning (see Table 3). For example, the teacher instructs students to make a scheme, think of examples, plan learning goals or invent test questions.

(5) Teacher as monitor. When students get more and more skilled in the use of certain learning and thinking strategies, the role of the teacher changes towards monitoring the use of these strategies in students' self-regulated learning. This role may well be combined with that of consultant, in which the teacher is one of the sources that students may consult. This makes it possible for teachers to take into account individual differences among students in their need for support. The teacher acts as external monitor and provides students with feedback on the quality of their strategy use (Volet, 1991; Lonka \& Ahola, 1995). After a phase of activation of thinking activities by teachers, this form of teacher-regulation is gradually withdrawn, too. By creating a challenging environment, the teacher capitalizes on the spontaneous and correct employment of the strategies by students (loose control). In Shuell's (1996) terms, the call on student-initiated use of the learning functions increases. The teacher can now shift attention to other learning functions that students have not yet mastered, or to more complex learning tasks.

(6) Teacher as evaluator. Process-oriented instruction also implies that teachers should evaluate the quality of students' strategy use. When teaching is directed at improving students' learning and thinking strategies, the extent to which this has been accomplished should be ascertained as well. This means that the employment of the thinking activities at which teaching is directed should be awarded in assessments. Tests may be composed on the basis of the processing functions described earlier. Students are asked, for example, to describe similarities and differences between particular theories, summarize the main points, give concrete examples, invent applications of what they learned, or draw their own conclusions about certain facts and compare them with the author's conclusions. The assessment of regulatory and affective skills is more complicated, and new forms of evaluation are needed for it. Advances in this field are, for example, portfolio assessments (e.g. Krause, 1996), which are used to assess reflective skills.

\section{Conclusions and discussion}

At a time when knowledge is getting obsolete ever faster and information is getting accessible ever easier via computer networks, the need for lifelong learning increases and teaching models based on transmission and storage of knowledge lose their 
functionality. Society's demand for new teaching models, aimed at developing students' ability to update their knowledge whenever necessary, is growing. Processoriented teaching models, focusing on the processes of knowledge construction and utilization, seem well suited to meeting these new demands. Especially integrating theories of learning and theories of teaching shows promising possibilities to develop learners' abilities to self-regulate their learning processes.

The perspective on learning and teaching outlined above has several advantages as compared to existing theories of learning and teaching. First, the concept of learning functions enables us to view learning and teaching processes in greater coherence than usual. The taxonomy of learning functions makes it possible to analyze selfregulated learning in terms of skill in different types of concrete learning activities. In this respect, it meets Winne's (1995) plea for "more basic research on details of knowledge and aspects of processing inherent in self-regulated learning" (p. 186). Secondly, the concept and taxonomy of learning functions unites two research fields that too often seemed to be separated: the research on (individual differences in) learning strategies and styles (e.g. Entwistle, 1992) and the research on self-regulated learning (e.g. Winne, 1995). In the theoretical framework described above, learning styles are conceived of as preferences for using certain learning functions. Selfregulated learning refers to students' skill in using a variety of learning functions and adapting this usage to the task demands at hand. Thirdly, especially the view that learning and teaching activities are images of each other and can be described in the same terms allows us, better than before, to examine the complex congruences and frictions occurring between students' learning activities and teachers' teaching activities in and outside of classroom situations. The conceptualization of learning and teaching strategies as different ways of dealing with the necessary learning functions contributes to a better integration of learning and teaching theories. When learning is increasingly seen as a process of self-regulated knowledge construction, teaching models should take this learning process as a point of departure. Fourthly, the perspective on congruence and friction between learning and teaching strategies makes it possible to identify learning tasks, situations, etcetera, that hinder or even impair the development of skill in self-regulated learning, and design learning tasks, materials and tests that stimulate this development. This is in line with Shuell's (1993) argument that "further advances in this understanding (of how students learn from instruction) need to consider the joint effects that teaching and learning have upon one another...". Finally, the concept of process-oriented teaching combines a set of instructional principles and teacher roles that all have proved to work when used in isolation. The combined use of these principles may well represent a very powerful learning environment. Recent studies by Volet et al. (1995), Vermunt (1995), Lonka (1997), and Schatteman, Carette, Couder and Eisendrath (1997) clearly demonstrate the importance of process-oriented teaching models at the university level.

Implications for practice. The model of learning and teaching outlined above offers opportunities for diagnosing current teaching practices in terms of their congruence or friction with student learning practices and of their call on certain learning activities. For example, analysis of the learning tasks, questions, assign- 
ments, and exam questions that teachers give to students in terms of the learning functions they take over, stimulate or capitalize on, often reveals that these tasks are very one-sided and more often reflect teachers' personal styles than students' needs. Mostly, teachers find these analyses very helpful to become aware of their blind spots and adjust their way of teaching. Moreover, the model points to the importance of an analysis of teaching/learning situations on the presence or absence of friction, on possibilities to create congruence and constructive friction, and on the actual division of learning functions among learners, teachers and learning materials. Such an analysis may reveal the absence of certain important learning functions and the over-representation of others. Besides, the perspective outlined here makes it possible both to concretize the learning functions and teaching strategies in domain-specific teaching, and at the same time to enable teachers from different domains to develop a common language to communicate about student learning. Since teachers' roles may change considerably as compared to more traditional classroom teaching, teacher training should focus more on the new roles of teachers as facilitators of student learning. Finally, a good example of the practical usage of the theoretical perspectives outlined thus far can be seen in the Netherlands. There, active and selfregulated learning, learning to learn, teaching how to learn, and dealing with individual differences will be leading teaching principles in the second phase of secondary education for the years to come, starting in 1998/1999. In this large-scale, nationwide innovation project, teachers, teacher educators, school principals, and researchers together try to develop a common language to communicate about student learning processes and to develop examples of good practice that foster active and self-regulated student learning in the different school subjects.

A research agenda. The theoretical perspective outlined in this article calls for further research and theory development. Many questions remain to be solved. From the above point of view, future research should be directed at the further development of a teaching and learning theory that puts learning processes into the focus of attention. Further research should be directed, for example, at clarifying relations between learning activities, prior knowledge and age of students, and subject domains. More research should also be done on the way teachers use the various teaching strategies and at what learning functions these strategies are directed. Moreover, too little is known about relations between craft knowledge and professional orientations of teachers on the one hand, and the way in which they deal with learning functions on the other hand. The way prospective and experienced teachers may acquire their new roles as diagnosticians, challengers, models, activators, monitors and evaluators of student learning needs to be addressed in research as well. We need to know more about congruence and friction between learning and teaching strategies, the way in which different levels of self-regulation and external regulation of learning processes operate upon one another and whether this interplay occurs differently in different kinds of learning environments. Forthcoming research should also be directed at the way the transition of teacher-regulation to student-regulation of learning processes can be concretely realized in different learning environments. An important responsibility for future research is the design of process-oriented teaching programs and to examine whether, how and why they work. 


\section{References}

Applebee, A. N., \& Langer, J. A. (1983). Instructional scaffolding: reading and writing as natural language activities. Language Arts, 60, 168-175.

Bednar, A. K., Cunningham, D., Duffy, T. M., \& Perry, J. D. (1991). Theory into practice: how do we link. In G. J. Anglin (Ed.), Instructional technology: past, present and future (pp. 88-101). Englewood, CO: Libraries Unlimited.

Beijaard, D., \& Verloop, N. (1996). Assessing teachers' practical knowledge. Studies in Educational Evaluation, 3, 275-286.

Bereiter, C., \& Scardamalia, M. (1989). Intentional learning as a goal of instruction. In L. B. Resnick (Ed.), Knowing, learning and instruction - essays in honor of Robert Glaser (pp. 361-392). Hillsdale, NJ: Erlbaum.

Biggs, J. B. (1987). Student approaches to learning and studying. Hawthorn, Victoria: Australian Council for Educational Research.

Biggs, J. (1996). Enhancing teaching through constructive alignment. Higher Education, 32, 347-364.

Billett, S. (1996). Situated learning: bridging sociocultural and cognitive theorising. Learning and Instruction, 6, 263-280.

Boekaerts, M. (1995). Self-regulated learning: bridging the gap between metacognitive and metamotivation theories. Educational Psychologist, 30, 195-200.

Brown, A. L. (1987). Metacognition, executive control, self-regulation and other more mysterious mechanisms. In F. E. Weinert \& R. H. Kluwe (Eds), Metacognition, motivation and understanding (pp. 65-116). Hillsdale, NJ: Erlbaum.

Brown, A. L. (1994). The advancement of learning. Educational Researcher, 23(8), 4-12.

Brown, J. S., Collins, A., \& Duguid, P. (1989). Situated cognition and the culture of learning. Educational Researcher, 18(1), 32-42.

Clark, R. E. (1990). When teaching kills learning: research on mathemathantics. In H. Mandl, E. de Corte, S. N. Bennett \& H. F. Friedrich (Eds), Learning and Instruction: European research in an international context, Vol. 2.2 (pp. 1-22). Oxford: Pergamon Press.

Collins, A., Brown, J. S., \& Newman, S. E. (1989). Cognitive apprenticeship: teaching the crafts of reading, writing and mathematics. In L. B. Resnick (Ed.), Knowing, learning and instruction - essays in honor of Robert Glaser (pp. 453-494). Hillsdale, NJ: Erlbaum.

Dahlgren, L. -O. (1984). Outcomes of learning. In F. Marton, D. Hounsell \& N. Entwistle (Eds), The experience of learning (pp. 19-35). Edinburgh: Scottish Academic Press.

De Corte, E. (1995). Fostering cognitive growth: a perspective from research on mathematics learning and instruction. Educational Psychologist, 30, 37-46.

Duffy, T. M., Lowyck, J., \& Jonassen, D. H. (Eds) (1993). Designing environments for constructive learning. New York: Springer Verlag.

Dweck, C. S. (1989). Motivation. In A. Lesgold \& R. Glaser (Eds), Foundations for a psychology of education (pp. 87-136). Hillsdale, NJ: Erlbaum.

Entwistle, N. (1992). The impact of teaching on learning outcomes in higher education - a literature review. Edinburgh: University of Edinburgh, Centre for Research on Learning and Instruction.

Entwistle, N. (1995). Frameworks for understanding as experienced in essay writing and in preparing for examinations. Educational Psychologist, 30, 47-54.

Ertmer, P. A., Newby, T. J., \& MacDougall, M. (1996). Students' responses and approaches to casebased instruction: The role of reflective self-regulation. American Educational Research Journal, 33, 719-752.

Gagné, R. M. (1970). The conditions of learning (2nd ed.). New York: Holt, Rinehart and Winston.

Gibbs, G., Morgan, A., \& Taylor, E. (1984). The world of the learner. In F. Marton, D. Hounsell \& N. Entwistle (Eds), The experience of learning (pp. 165-188). Edinburgh: Scottish Academic Press.

Glaser, R. (1991). The maturing of the relationship between the science of learning and cognition and educational practice. Learning and Instruction, 1, 129-144.

Halpern, D. F., Hansen, C., \& Riefer, D. (1990). Analogies as an aid to understanding and memory. Journal of Educational Psychology, 82, 298-305. 
Hamaker, C. (1986). The effects of adjunct questions on prose learning. Review of Educational Research, $56,212-242$.

Hidi, S. (1990). Interest and its contribution as a mental resource for learning. Review of Educational Research, 60, 549-571.

Iran-Nejad, A. (1990). Active and dynamic self-regulation of learning processes. Review of Educational Research, 60, 573-602.

Janssen, P. J. (1996). Studaxology: the expertise students need to be effective in higher education. Higher Education, 31, 117-141.

Kember, D. (1991). Instructional design for meaningful learning. Instructional Science, 20, 289-310.

Kirby, J. R., \& Pedwell, D. (1991). Students' approaches to summarisation. Educational Psychology, 11, 297-307.

Krause, S. (1996). Portfolios in teacher education: effects of instruction on preservice teachers' early comprehension of the portfolio process. Journal of Teacher Education, 47, 130-138.

Lohman, D. F. (1986). Predicting mathemathantic effects in the teaching of higher order skills. Educational Psychologist, 21, 191-208.

Lonka, K. (1997). Explorations of constructive processes in student learning. Doctoral thesis, Department of Psychology, University of Helsinki.

Lonka, K., \& Ahola, K. (1995). Activating instruction — how to foster study and thinking skills in higher education. European Journal of Psychology of Education, 10, 351-368.

Lonka, K., \& Lindblom-Ylänne, S. (1996). Epistemologies, conceptions of learning, and study practices in medicine and psychology. Higher Education, 31, 5-24.

Lowyck, J., \& Elen, J. (1993). Transitions in the theoretical foundation of instructional design. In T. M. Duffy, J. Lowyck \& D. H. Jonassen (Eds.), Designing environments for constructive learning (pp. 213-230). New York: Springer Verlag.

Marton, F. (1988). Describing and improving learning. In R. R. Schmeck (Ed.), Learning strategies and learning styles (pp. 54-82). New York: Plenum Press.

McCombs, B. L. (1991). Motivation and lifelong learning. Educational Psychologist, 26, 117-127.

Meyer, J. H. F. (1996). Some aspects of the individual difference modelling of causal attribution. Higher Education, 31, 51-71.

Meyer, E., \& Cleary, E. G. (1997). Toward an "interference" model of student learning in medicine. Paper presented at the 7th conference of the European Association for Research on Learning and Instruction, Athens, August.

Moran, A. (1991). What can learning styles research learn from cognitive psychology? Educational Psychology, 11, 239-245.

Palincsar, A. S., \& Brown, A. L. (1989). Classroom dialogues to promote self-regulated comprehension. In J. Brophy (Ed.), Advances in research on teaching, Vol. 1 (pp. 35-67). Greenwich, CO: JAI Press.

Pask, G. (1976). Styles and strategies of learning. British Journal of Educational Psychology, 46, 128-148.

Paul, R. W. (1990). Critical and reflective thinking: a philosophical perspective. In B. F. Jones \& L. Idol (Eds), Dimensions of thinking and cognitive instruction (pp. 445-494). Hillsdale, NJ: Erlbaum.

Pintrich, P. R. (1994). Continuities and discontinuities: future directions for research in educational psychology. Educational Psychologist, 29, 137-148.

Prosser, M., Trigwell, K., \& Taylor, P. (1994). A phenomenographic study of academics' conceptions of science learning and teaching. Learning and Instruction, 4, 217-231.

Reynolds, R. E., \& Shirey, L. L. (1988). The role of attention in studying and learning. In C. E. Weinstein, P. A. Alexander \& E. T. Goetz (Eds), Learning and study strategies: issues in assessment, instruction, and evaluation (pp. 77-100). New York: Academic Press.

Rosenshine, B., Meister, C., \& Chapman, S. (1996). Teaching students to generate questions: a review of intervention studies. Review of Educational Research, 66, 99-136.

Rosenshine, B., \& Stevens, R. (1986) Teaching functions. In M. C. Wittrock (Ed.), Handbook of research on teaching (3rd ed.) (pp. 376-391). New York: MacMillan.

Säljö, R. (1979). Learning in the learner's perspective. I. Some common sense conceptions. Reports from the Department of Education, University of Göteborg, No. 76.

Scardamalia, M., \& Bereiter, C. (1994). Computer support for knowledge building communities. Journal of the Learning Sciences, 3, 265-283. 
Schatteman, A., Carette, E., Couder, J., \& Eisendrath, H. (1997). Understanding the effects of a processoriented instruction in the first year of university by investigating learning style characteristics. Educational Psychology, 17, 111-125.

Schellings, G. L. M., Van Hout-Wolters, B. H. A. M., \& Vermunt, J. D. (1996). Individual differences in adapting to three different tasks of selecting information from texts. Contemporary Educational Psychology, 21, 423-446.

Schmeck, R. R., Geisler-Brenstein, E., \& Cercy, S. P. (1991). Self-concept and learning: the revised inventory of learning processes. Educational Psychology, 11, 343-362.

Schoenfeld, A. H. (1988). When good teaching leads to bad results: the disaster of "well-taught" mathematics courses. Educational Psychologist, 23, 145-166.

Short, E. J., \& Weisberg-Benchell, J. A. (1989). The triple alliance for learning: cognition, metacognition, and motivation. In C. B. McCormick, G. E. Miller \& M. Pressley (Eds), Cognitive strategy research: from basic research to educational applications (pp. 33-63). New York: Springer Verlag.

Shuell, T. J. (1993). Toward an integrated theory of teaching and learning. Educational Psychologist, 28, 291-311.

Shuell, T. J. (1996). Teaching and learning in a classroom context. In D. C. Berliner \& R. C. Calfee (Eds), Handbook of Educational Psychology (pp. 726-764). New York: Simon and Schuster Macmillan.

Simons, P. R. J. (1993). Constructive learning: the role of the learner. In T. M. Duffy, J. Lowyck \& D. H. Jonassen (Eds), Designing environments for constructive learning (pp. 291-314). New York: Springer Verlag.

Snow, R. E., Corno, L., \& Jackson, D. (1996). Individual differences in affective and conative functions. In D. C. Berliner \& R. C. Calfee (Eds), Handbook of educational psychology (pp. 243-310). New York: Simon and Schuster Macmillan.

Sternberg, R. J., \& Horvath, J. A. (1995). A prototype view of expert teaching. Educational Researcher, 24(6), 9-17.

Vermetten, Y., Lodewijks, H., \& Vermunt, J. (1997). Change and stability in learning strategies during the first two years at the university. Paper presented at the annual meeting of the American Educational Research Association, Chicago, March.

Vermunt, J. D. (1995). Process-oriented instruction in learning and thinking strategies. European Journal of Psychology of Education, 10, 325-349.

Vermunt, J. D. (1996). Metacognitive, cognitive and affective aspects of learning styles and strategies: a phenomenographic analysis. Higher Education, 31, 25-50.

Vermunt, J. D. (1998). The regulation of constructive learning processes. British Journal of Educational Psychology, 68, 149-171.

Volet, S. E. (1990). Goals in the adaptive learning of university students. In H. Mandl, E. de Corte, S. N. Bennett \& H. F. Friedrich (Eds), Learning and instruction - European research in an international context, Vol. 2.1 (pp. 497-516). Oxford: Pergamon Press.

Volet, S. E. (1991). Modelling and coaching of relevant metacognitive strategies for enhancing university students' learning. Learning and Instruction, 1, 319-336.

Volet, S., McGill, T., \& Pears, H. (1995). Implementing process-based instruction in regular university teaching: conceptual, methodological and practical issues. European Journal of Psychology of Education, 10, 385-400.

Von Wright, J. (1992). Reflections on reflection. Learning and Instruction, 2, 59-68.

Vygotsky, L. S. (1978). Mind in society: the development of higher psychological processes. Cambridge, MA: Harvard University Press.

Wagner, E. D., \& McCombs, B. L. (1995). Learner-centered psychological principles in practice: designs for distance education. Educational Technology, 35(3), 32-35.

Weiner, B. (1994). Integrating social and personal theories of achievement striving. Review of Educational Research, 64, 557-573.

Winne, P. H. (1995). Inherent details in self-regulated learning. Educational Psychologist, 30, 173-187.

Zimmerman, B. J., \& Bandura, A. (1994). Impact of self-regulatory influences on writing course attainment. American Educational Research Journal, 31, 845-862. 